Supporting Information.

\title{
In vitro and in vivo Characterization of a Foam-like Polyurethane Bone Adhesive for Promoting Bone Tissue Growth
}

Kun Lei, ${ }^{a+}$ Qi Zhu, ${ }^{a}+$ Xinling Wang, ${ }^{a}$ Haijun Xiao, ${ }^{b *}$ Zhen Zheng ${ }^{a *}$

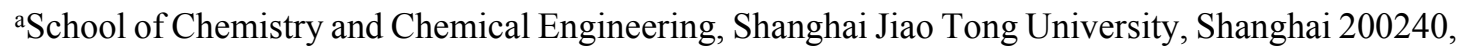
China.

bepartment of Orthopedics, Central Hospital of Fengxian District, Sixth People's. Hospital of Shanghai, Shanghai 201400, China.

\section{Corresponding Author}

Prof. Zhen Zheng; Prof. Haijun Xiao

*E-mail: zzheng@sjtu.edu.cn (Z. Z); xiaohaijun89@126.com (H. J. X). 
Scheme 1. Reaction between isocyanate and hydroxyl groups

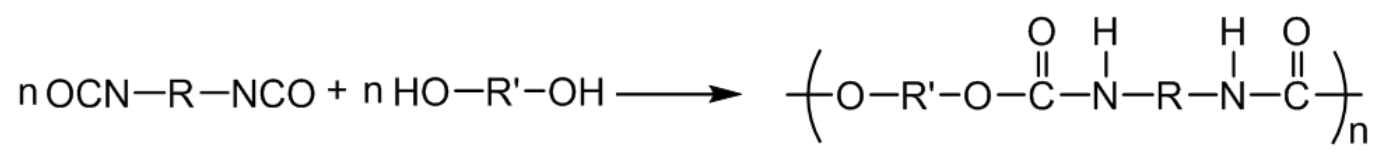

Scheme 2. Reaction between isocyanate and water
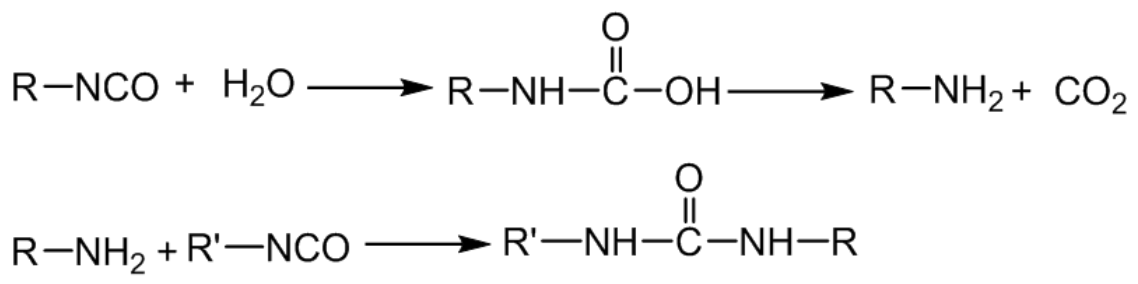

Figure S1. The chemical reaction of polyurethane.
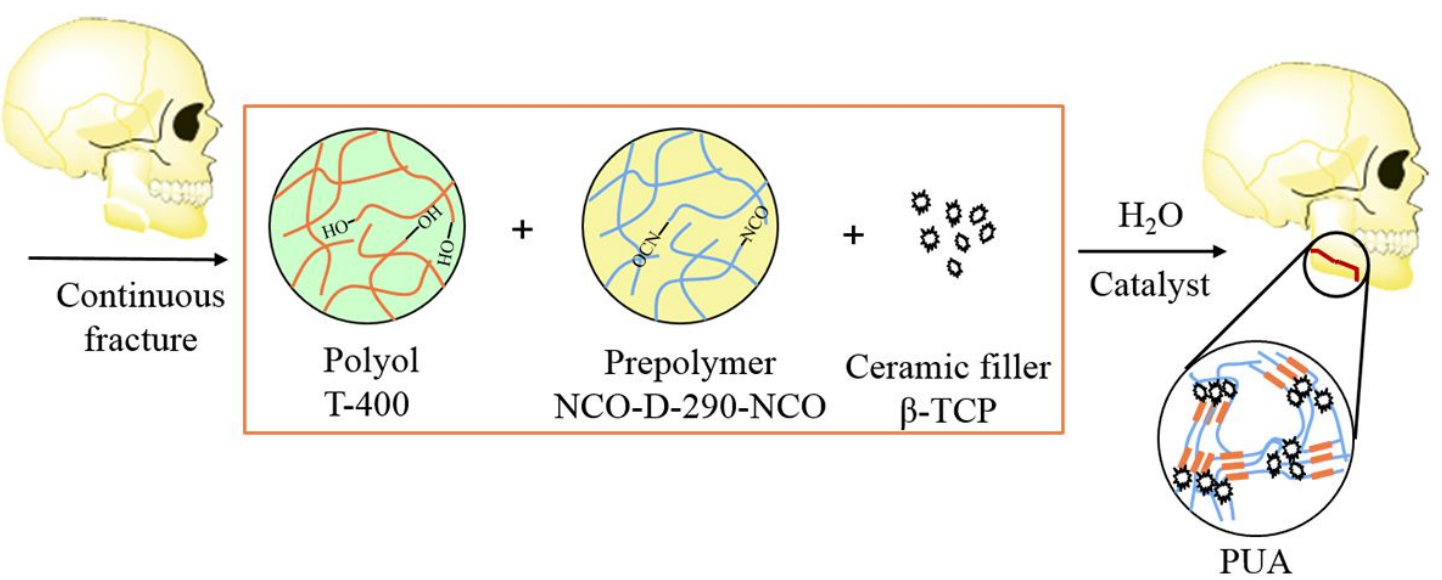

Figure S2. The TOC image of this article

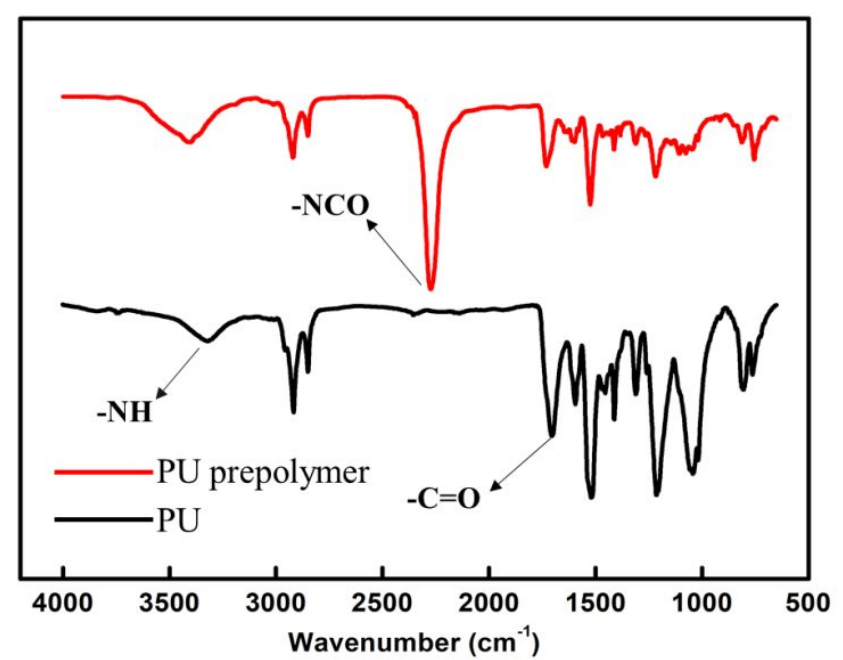

Figure S3. The IR characterization of PU prepolymer, and PU 


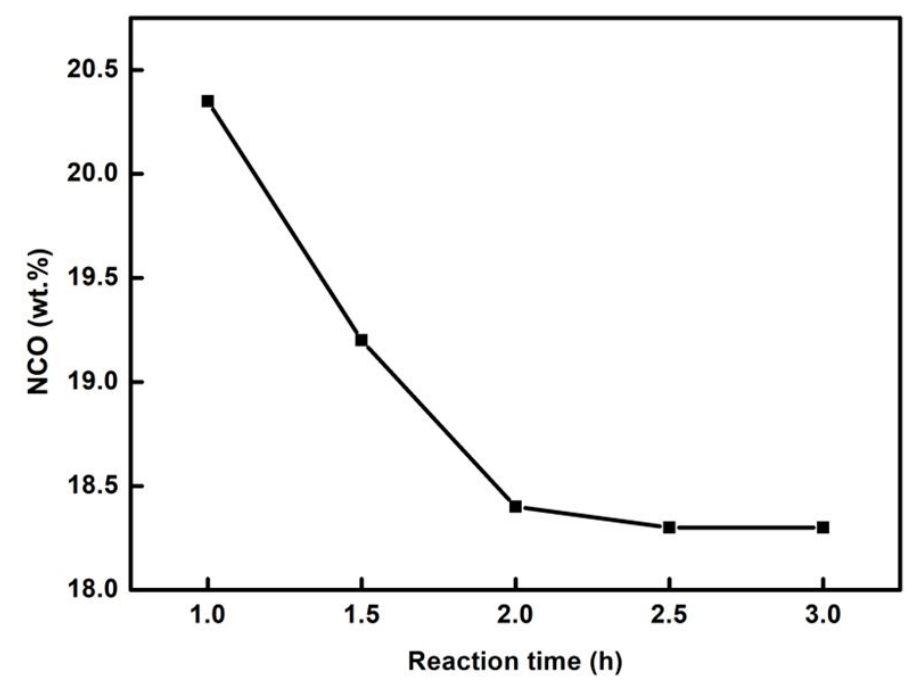

Figure S4. Change of isocyanate mass fraction with reaction time for the preparation of polyurethane prepolymer
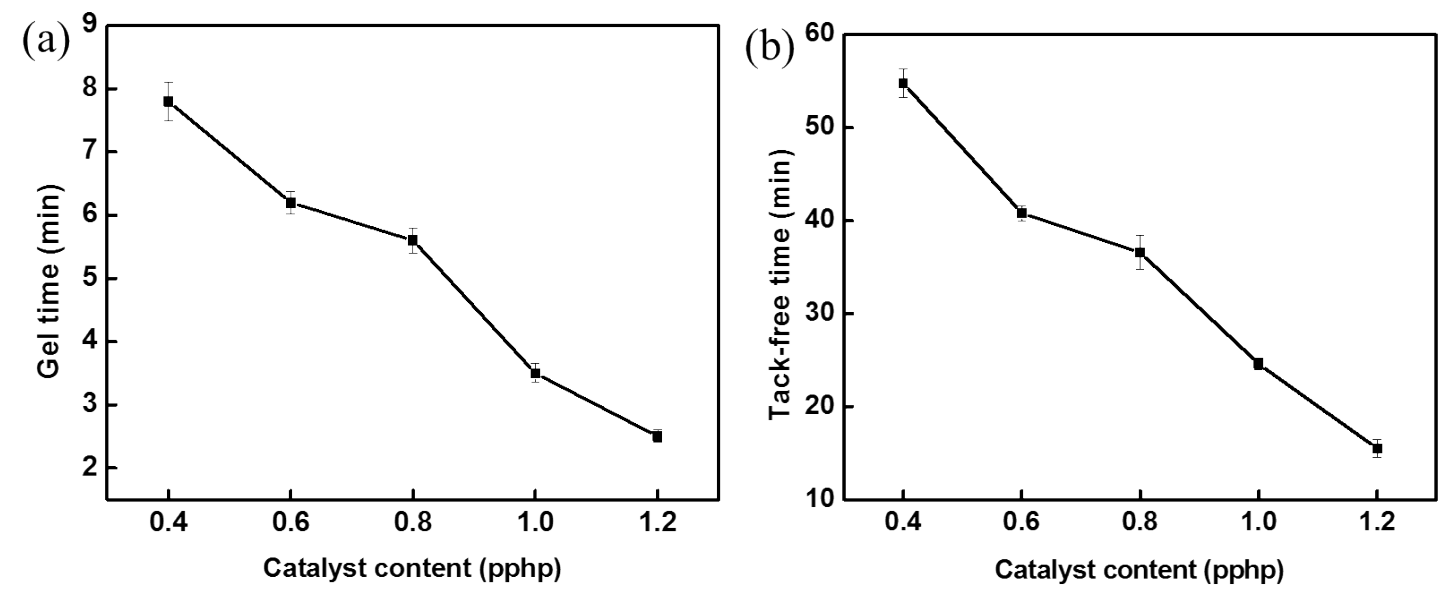

Figure S5. The effect of catalyst content on the gel time (a) and tack-free time (b) of PUAs
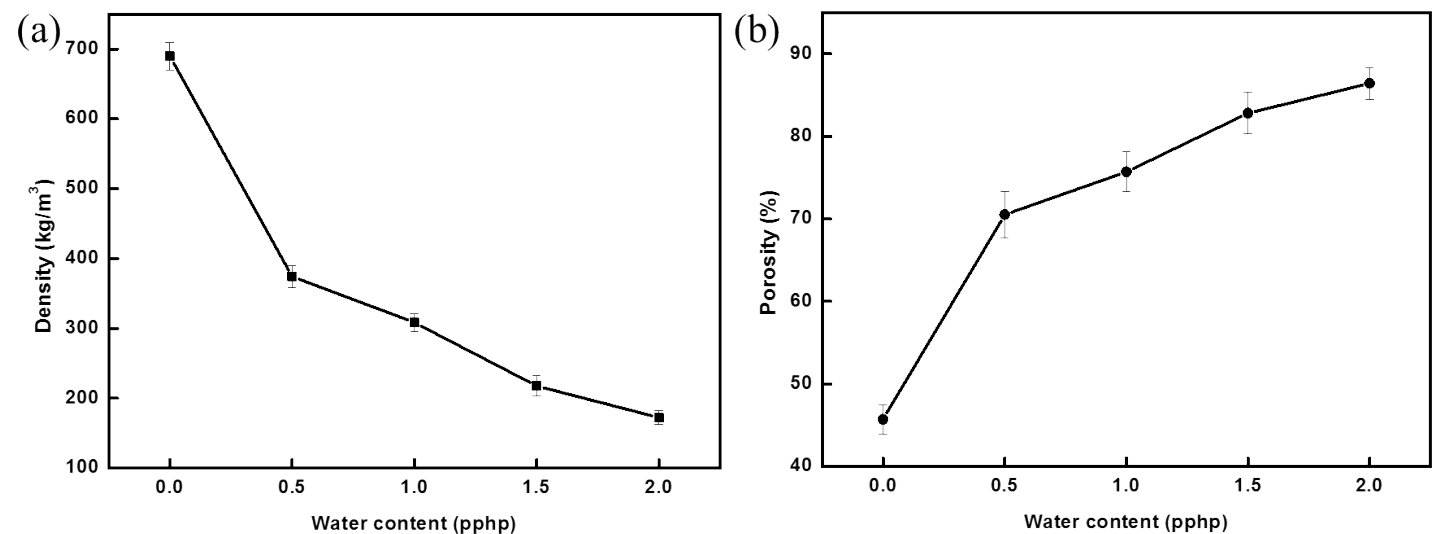

Figure S6. The effect of water content on the density (a) and the porosity (b) of PUAs 


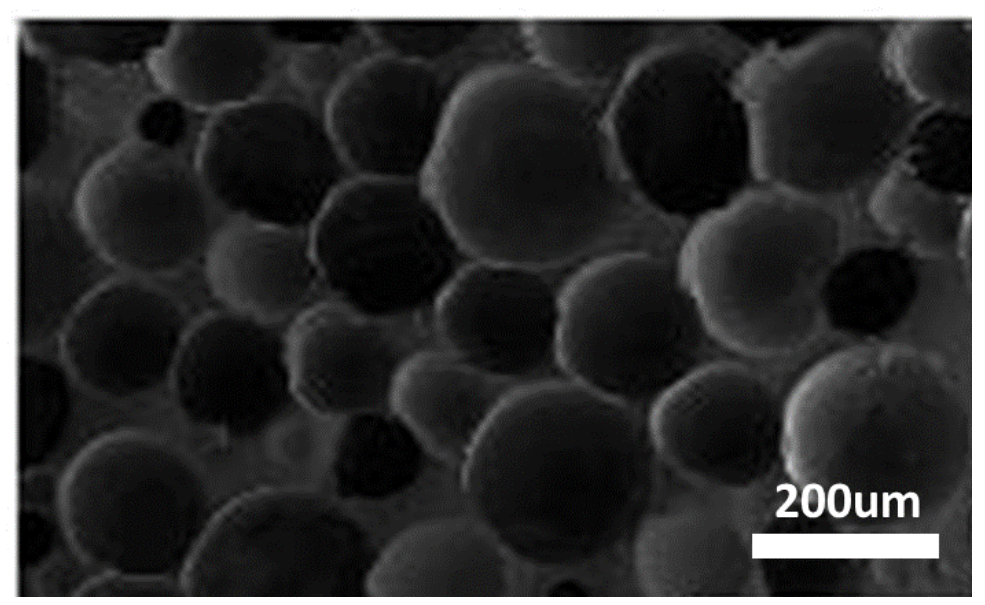

Figure S7. The SEM image of PU-8
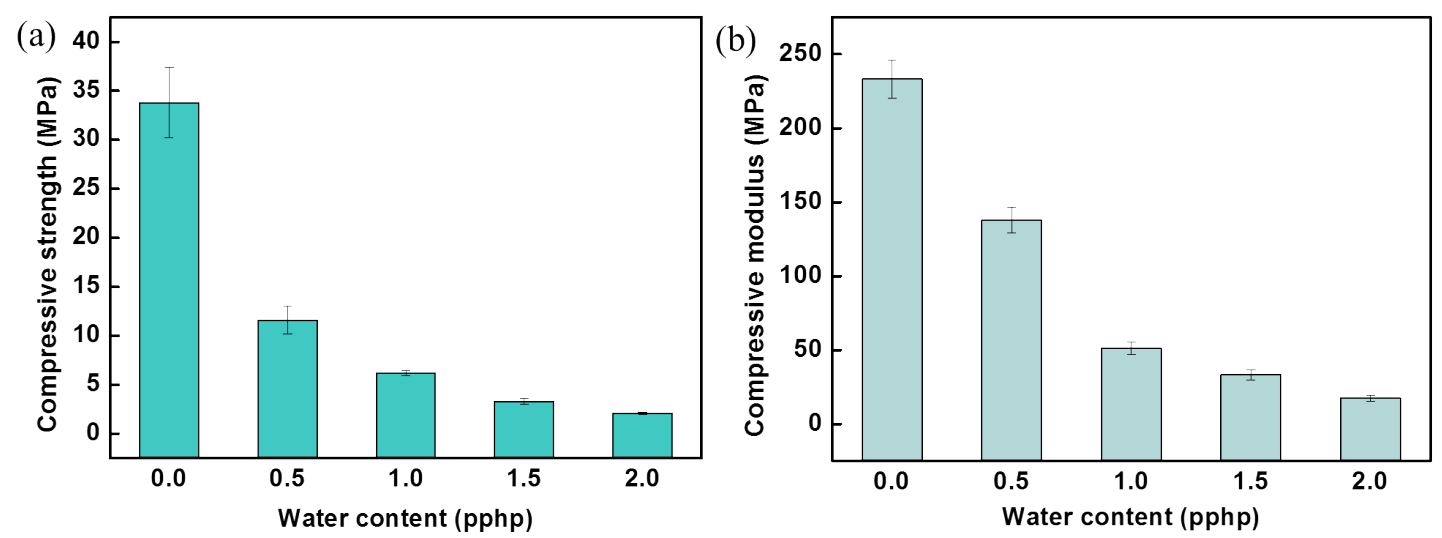

Figure S8. The effect of water content on the compressive strength (a) and compressive modulus (b) of PUAs

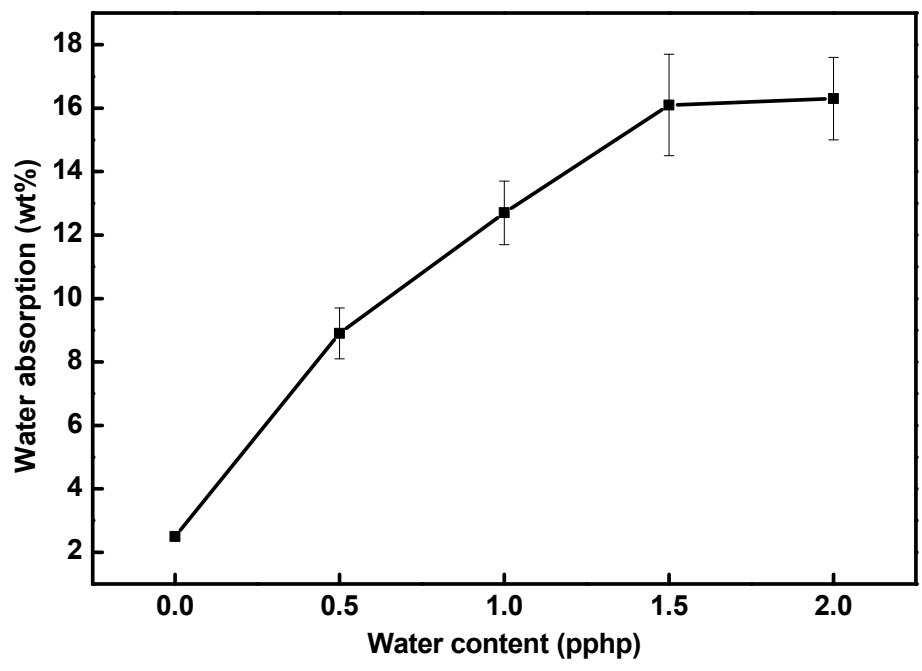

Figure S9. The effect of water content on the water absorption of PUAs 


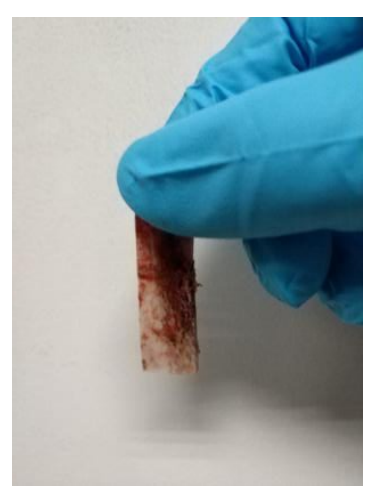

Figure S10. A bone sample after bonded by the adhesive 